\title{
Adverse selection, moral hazard and propitious selection $^{1}$
}

\author{
Philippe De Donder ${ }^{2} \quad$ Jean Hindriks ${ }^{3}$
}

First version: December 2006

This version: May 2008

\footnotetext{
${ }^{1}$ Previous versions of this paper have circulated under the title "Does propitious selection explain why riskier people buy less insurance?". The paper has been revised while the first author was visiting Yale University. He thanks Yale's Economics Department for its hospitality. We thank two referees and the Editor for helpful comments. All remaining errors are ours.

${ }^{2}$ Toulouse School of Economics (GREMAQ-CNRS \& IDEI). 21 allée de Brienne, 31000 Toulouse, France. Email: dedonder@cict.fr. Tel.: +33.561.128.603. Fax: $+33.561 .128 .637$

${ }^{3}$ Department of Economics and CORE, Université Catholique de Louvain.
} 


\begin{abstract}
We propose a simple model with preference-based adverse selection and moral hazard that formalizes the cherry picking/propitious selection argument. This argument assumes that individuals differ in risk aversion, potentially resulting in more risk-averse agents buying more insurance while being less risky. The propitious selection argument is summarized by two properties: regularity (more risk averse agents exert more caution) and single-crossing (more risk averse agents have a higher willingness to pay for insurance). We show that these assumptions are incompatible with a pooling equilibrium, and that they do not imply a negative correlation between risk and insurance coverage at equilibrium.
\end{abstract}

Keywords: cherry picking, propitious selection, advantageous selection, precaution choice, social insurance

JEL Classification: D82, G22. 
Most economic papers on insurance assume some form of asymmetric information. The insured is assumed to either have information that is relevant to the contract but that is unknown to the insurer (adverse selection) or to be able to perform some relevant action that is hidden to the insurer (moral hazard). In either case, asymmetric information has been shown to produce a positive correlation between risk and insurance demand in equilibrium. In the case of adverse selection, high risk individuals buy more insurance while, in moral hazard settings, agents who, for some unexplained reasons, pick up insurance with less coverage are encouraged to exert more effort, resulting in a lower (endogenous) risk. Chiappori and Salanié (2000) stress that the positive correlation between risk and insurance demand is fairly robust in theory. For instance, it does not depend on the market structure (perfect competition or monopoly), nor on specific properties of preferences (such as single crossing).

However, there is scant empirical evidence of such a positive correlation. Chiappori and Salanié (2000) use various parametric and non parametric methods and find no evidence of a positive correlation in a French survey of automobile insurance contracts. Saito (2006) comes to the same conclusion with a Japanese data set also on automobile insurance. On the contrary, various authors find evidence of a negative correlation: de Meza and Webb (2001) for credit card purchase insurance (a lower proportion of credit cards 
are reported stolen among those that are insured than among the uninsured), Cawley and Philipson (1999) for the life insurance market (those who purchase life insurance have a lower death rate than those who do not, even after controlling for factors such as smoking status and income) and Finkelstein and McGarry (2003) for health care (people who spend more on their own health both buy more insurance and are less likely to use long-term nursing home care). ${ }^{1}$

Several explanations have been proposed for this negative correlation. Chiappori et al. (2006) stress the role of imperfect competition and optimal rent extraction by insurance companies. Villeneuve (2000) turns the asymmetric information on its head by assuming that the insurer knows more than the insured and shows that this may generate a negative correlation within a principal-agent framework. In this paper, we concentrate on one explanation that seems to gain in popularity: preference-based adverse selection. Chiappori and Salanié (2000) calls this “(...) the so-called cherry-picking story. Assume that individuals have different risk aversions and that more riskaverse drivers tend to both buy more insurance and drive more cautiously; this would even suggest a negative correlation between insurance coverage and accident frequency" (p. 19, their emphasis). The same argument has been called "propitious selection" by Hemenway (1990) who also assumes

\footnotetext{
${ }^{1}$ See also Hemenway (1992).
} 
that potential insurance buyers have different tastes for risk and that they are consistent in their taste for risk across physical and financial dimensions. To quote him, "The implication is that individuals who are highly risk avoiding are more likely both to try to reduce the hazard and to purchase insurance" (p. 1064), possibly resulting in a negative correlation between risk and insurance purchases.

The cherry-picking/propitious selection argument is very appealing. It seems very reasonable that agents differ according to their taste for risk, and that this information is a priori unknown to the insurer. Several empirical studies have shown that individuals who engage in risky behavior (or who do not engage in risk reducing behavior) are less likely to hold various types of insurance: life insurance, acute private health insurance, annuities, long term care insurance and Medigap (Cutler, Finkelstein and McGarry (2008)) or generally medical insurance (Lloyd, Lauderdale and Betz (1987) for unhelmeted motorcyclists, Nelson et al. (1993) and Clyde, Hemenway and Nagurney (1996) for unbelted motorists and Viscusi and Hakes (2008) for smokers).

The purpose of this paper is to provide a reasonable formalization of the propitious/cherry picking argument and to verify that it can explain that good risks buy more insurance. We develop a simple insurance model with moral hazard and adverse-selection based on risk aversion. We assume two 
types of individuals differing in risk aversion. The game we model has three stages: first, firms offer a menu of insurance contracts. ${ }^{2}$ Second, individuals choose which contract if any to buy depending on their risk aversion. Finally, given the contract chosen, they decide how much precaution to exert.

Our results are threefold. First, we make explicit two key properties underlying the cherry picking/propitious selection argument: regularity (precaution is increasing with risk aversion for any coverage rate) and single crossing (conditional on precaution choice, the marginal willingness to pay for insurance increases with risk aversion for any coverage rate). To be clear, we do not claim that these two properties are necessary to generate a negative correlation between risk and insurance, but rather that, in the context of our model, they formalize the cherry picking argument. Together, they imply that, in Chiappori and Salanié (2000) terms, "more risk-averse drivers tend to both buy more insurance and drive more cautiously". We also show that, although these properties may be internally consistent, they are not easily obtained in the context of expected utility theory.

Second, we show that, in the context of our model, these two properties

\footnotetext{
${ }^{2}$ Unlike the empirical tests of propitious selection cited above which compare individuals with and without insurance, our model considers insurance contracts offering incomplete coverage. For a study of the trade-offs between exclusion and coverage, see De Feo and Hindriks (2005).
} 
imply that there is no pooling equilibrium. ${ }^{3}$ Our main result then consists in showing that these properties do not suffice to guarantee a negative correlation between risk levels and insurance purchases, because of the equilibrium behavior of the insurance providers. We show that, in order to separate individuals according to their risk preferences, the insurance companies must offer the more risk averse individuals more insurance than they would like (over-insurance). This in turn reduces their level of precaution, possibly to the point where they become riskier than those who buy less insurance because they are less risk averse. To obtain the negative correlation between risk and insurance purchases, one further needs the extra condition of marginal willingness to pay decreasing with coverage for the less risk averse individuals. This condition would be satisfied with decreasing marginal utility of income, in the absence of moral hazard. However, with moral hazard, the adverse effect of insurance on precaution can produce an increasing marginal willingness to pay for insurance. We provide in the Appendix an example, based on Yaari's (1987) dual theory of choice under risk for which the regularity and single-crossing properties are both satisfied, but where the marginal willing-

\footnotetext{
${ }^{3}$ This is sharp contrast to de Meza and Webb (2001) who develop a model with moral hazard and adverse selection on risk in the presence of loading where equilibria can be either pooling or semipooling. Their result is due to the fact that preferences are not single-crossing in their framework.
} 
ness to pay for insurance is increasing (since marginal utility of income is constant) so that we obtain a positive correlation between risk and insurance purchases.

Finally, the cherry picking/propitious selection argument as we model it has also very important normative and policy implications for social insurance, even when it generates a positive correlation between risk and insurance purchases. We illustrate this by showing that the introduction of a mandatory pooling social insurance scheme that agents can complement with private insurance may be Pareto damaging. The intuition for this result is as follows: less risk averse agents exhibit lower risk in equilibrium, due to the fact that they buy less insurance, and thus suffer from being pooled with more risky individuals. This in turn induces the private insurance market to increase overprovision to separate the more risk averse individuals. If more risk averse agents are numerous enough, the extra cost of overinsurance dominates the cross-subsidy benefit, so that they also lose from the introduction of social insurance.

\section{Propitious selection and private insurance}

We model an economy where all individuals face the same potential monetary loss $L$. We study a three-stage game with two types of individuals who differ 
only in risk aversion, which is not observable by insurance providers. In the first stage, zero-profit insurance contracts are offered to the agents. They consist of a premium $\pi$ and of a coverage rate $\delta$, i.e. the fraction of the damage that will be reimbursed by the insurer in case the damage occurs. In the second stage, individuals choose which, if any, private contract to buy. In the last stage, they decide how much precaution to exert.

As usual, we solve this game backwards, starting with the precaution choice.

\subsection{The precaution choice}

The individual preferences over lotteries are represented by the von-NeumanMorgenstein ${ }^{4}$ utility function $u_{\theta}$, with $\theta$ denoting the individual risk aversion level. Risk aversion is the only heterogeneity between individuals. We only consider two levels of risk aversion, $\theta \in\{L, H\}$, where an individual exhibits a high risk aversion (type $H$ ) if her utility function $u_{H}$ is obtained by an increasing concave transformation of $u_{L}$.

We assume that all individuals have access to the same technology $p(e)$ which gives the loss probability $p$ as a function of the (unobservable) amount

\footnotetext{
${ }^{4}$ Although we frame the analysis in the text in expected utility terms, our reasoning would equally apply to other ways to model preference over lotteries. The Appendix develops a model using Yaari's (1987) dual theory of choice under uncertainty.
} 
of precaution $e$ they exert. The function $c(e)$ denotes the non-monetary $\operatorname{cost}^{5}$ as a function of precaution effort. The cost of precaution is the same for all individuals. We assume that $p(e)$ is decreasing while $c(e)$ is increasing and convex.

The expected utility of an individual of type $\theta$ who exerts precaution $e$ and buys the insurance contract $(\pi, \delta)$ is

$$
\begin{aligned}
U_{\theta}(e, \pi, \delta)= & p(e) u_{\theta}(w-\pi-(1-\delta) L) \\
& +(1-p(e)) u_{\theta}(w-\pi)-c(e)
\end{aligned}
$$

where $w$ denotes the wealth endowment.

In our model, the risk level $p$ is endogenously determined by the optimal precaution choice of the agent. The optimal precaution choice $e_{\theta}(\delta, \pi)$ of type $\theta$ given the insurance contract $(\delta, \pi)$ is given by

$$
e_{\theta}(\delta, \pi)=\arg \max _{e \geq 0} U_{\theta}(e, \pi, \delta)
$$

The optimal precaution decreases with the coverage rate, and so the risk level of any individual increases with coverage rate. This is the moral hazard effect. The optimal precaution with full coverage is zero for all. The cherry picking/propitious selection argument first assumes that

\footnotetext{
${ }^{5}$ We discuss after Property 1 the alternative modelling assumption of a monetary cost of effort.
} 
Property 1 (Regularity): For any insurance contract, the more risk averse individual exerts more precaution.

This property does not always hold with expected utility functions. Jullien et al. (1999) give sufficient conditions for more risk averse individuals to exert more precaution. ${ }^{6}$ This requires in particular partial insurance because complete insurance induces minimum prevention and maximum risk for all individuals regardless of risk aversion. Jullien et al. (2007) argue that the most appropriate way to model the cost of precaution is to use a monetary cost like $U(R-c(e))$, so that the marginal rate of substitution between precaution and wealth does not depend on the shape of the utility function. With this monetary formulation, they show that the regularity property does not necessarily hold. The reason is that precaution reduces wealth even in the event of a loss, so that more risk averse agents may choose to save on the cost of precaution to increase their wealth in the bad state. Obviously, for this effect to arise, the loss probability has to be sufficiently high.

\subsection{The demand for insurance}

We now look at individual preferences over insurance contracts $(\pi, \delta)$. Plugging the optimal precaution choice (2) in the utility function (1), we obtain

\footnotetext{
${ }^{6}$ Eeckhoudt and Gollier (2005) focus on the impact of prudence (i.e., a positive third derivative of the utility function) on precaution.
} 
the indirect utility function of type $\theta$ for an insurance contract. A crucial question in terms of indirect preferences is whether they satisfy the singlecrossing property, (i.e. whether marginal willingness to pay for insurance is monotone in risk-aversion). There are two opposite effects at play. On the one hand, a higher risk-aversion results in a higher willingness-to-pay for insurance given the same risk level. On the other hand, more risk averse agents may exert more precaution and end up being less risky, which lowers their willingness to pay for insurance. The cherry picking/propitious selection argument implicitly assumes that:

Property 2 (Single crossing): Given the optimal precaution choice, for any insurance contract, the marginal willingness to pay for insurance is higher for the more risk averse individual.

In words, the preference effect dominates the risk effect on the willingness to pay for insurance, for any given insurance contract, so that the more risk averse individuals are more willing to pay for insurance even though they face lower risk by behaving more cautiously. Jullien et al. (2007) show that the single-crossing property always holds with the monetary formulation of the cost of precaution. De Meza and Webb (2001) show that the singlecrossing condition between risk-neutral and risk averse individuals may not be satisfied with non-monetary costs of precaution.

To summarize, Properties 1 and 2 together embody the cherry pick- 
ing/propitious selection argument in our three-stage model: the more risk averse individuals will both exert more precaution (given any insurance contract) and have a higher willingness to pay for insurance (given their optimal precaution choice).

\subsection{Equilibrium insurance contracts}

We now solve the first stage of the game assuming that Properties 1 and 2 (as implied by the propitious selection argument) hold, and we look at the equilibrium insurance contracts these properties imply. Consider that low risk aversion individuals (denoted by type $L$ ) are in proportion $\lambda$ and high risk aversion individuals (type $H$ ) are in proportion $1-\lambda$. We first show using Figure 1 that there cannot exist a pooling equilibrium with partial coverage.

[Insert Figure 1: Non existence of pooling equilibria]

The plain curves represent the fair price for each type, denoted by $\pi(i), i=$ $\{L, H\}$. Regularity ensures that type $L$ agents are more risky than type $H$ agents, for any given coverage rate $0<\delta<1$, and thus that $\pi(L)$ lies everywhere above $\pi(H)$, except for $\delta \in\{0,1\}$. The fair price when both types are lumped together and charged the same price is represented by the 
dashed curve whose formula is given by $\lambda \pi(L)+(1-\lambda) \pi(H)$. Due to moral hazard, the fair price is an increasing and convex function of coverage rate for both types. We have also depicted the single-crossing indifference curves of the two types (labelled $v_{L}$ and $v_{H}$ ) passing through a pooling contract with partial coverage ${ }^{7}$. It is clear from the graph that given this pooling contract, it is always possible for an insurer to propose a contract that can attract only the more risk averse (who are also less risky by the regularity property) and make a positive profit. This separation is possible given the single-crossing property of indifference curves.

Likewise, Figure 1 also makes clear that a pooling contract with full coverage can not be an equilibrium, since it would be possible to offer a contract with less coverage that attracts the more risk averse type (possibly together with the less risk averse) and makes a positive profit.

Result 1 Under Properties 1-2, there is no equilibrium pooling insurance contract.

Figure 2 illustrates the existence of a separating equilibrium. In this equilibrium, the less risk averse individuals obtain their most-preferred contract (i.e. point $A$ ). Whenever the incentive compatibility constraint of type $L$ is binding at equilibrium (which is the case in Figure 2 since all feasible

\footnotetext{
${ }^{7}$ Although all Figures have been drawn with convex indifference curve, the reader can check that convexity plays no role in Figures 1 and 2.
} 
contracts preferred by type $H$ to $B^{\prime}$-the shaded area- are also preferred by type $L$ individuals to contract $A$ ), type $H$ individuals are proposed a fair contract with more coverage than they would wish. The intuition for this equilibrium is that it is necessary to overprovide insurance to the more risk averse individuals in order to separate them from the less risk averse. Observe that type $H$ always buys more insurance than type $L$ at equilibrium, in accordance with the propitious selection argument.

[Insert Figure 2: Separating equilibrium with overinsurance]

We are now in position to make our central point that the correlation between risk and insurance demand is a priori ambiguous at equilibrium. On one hand, more risk averse individuals are less risky than less risk averse individuals if they all face the same coverage rate. On the other hand, in the separating equilibrium more risk averse agents get more insurance, which reduces their relative level of precaution. Figure 3 shows that more risk averse individuals are in fact more risky, in any separating equilibrium, if the indifference curve of the less risk averse individuals through this contract is convex.

[Insert Figure 3: Relative risks in separating equilibria] 
The straight bold line going through point $A$ shows all fair contracts with a risk level equal to that optimally chosen by type $L$ at point $A$. The intersection (denoted by $B^{\prime}$ ) between type $L$ 's indifference curve through $A$ (denoted by $v_{L}$ ) and $\pi(H)$ gives us the minimum amount of coverage bought by type $H$ at the separating equilibrium. To prove that type $H$ is riskier at equilibrium than type $L$, we then have to prove that $B^{\prime}$ lies above the bold straight line through $A$. Observe first that the slope of the straight line through $A$ is lower than the slope of $\pi(L)$ at $A$, since the risk increases along the latter due to moral hazard. On the other hand, the slope of $v_{L}$ is equal to the slope of $\pi(L)$ at point $A$, by optimality of $A$ for type $L$. We then obtain that a convex indifference curve $v_{L}$ lies above the straight line through $A$ to the right of $A$, so that its intersection with $\pi(H)$ also lies above $B^{\prime}$. This means that type $H$ is more risky than type $L$ at any separating equilibrium, and that risks and demand of insurance are positively correlated.

We then obtain the follow result.

Result 2 Under Properties 1-2, the equilibrium insurance contracts are separating, with the more risk averse individuals buying more coverage. Moreover, the more risk averse individuals display higher (lower) risk if the marginal willingness to pay for insurance of the less risk averse individual is increasing (decreasing) with coverage. 
We thus obtain that Properties 1 and 2 are not sufficient for the negative correlation between insurance coverage and risk to emerge. Even though more risk averse agents tend to behave more cautiously, they also buy more insurance at equilibrium. This in turn induces the more risk averse individuals to behave less cautiously than the less risk averse individuals who purchase less insurance. To obtain that more risk averse individuals are less risky at equilibrium, we need the extra condition that the willingness to pay for insurance of the less risk averse individuals be decreasing with coverage.

Observe that there are two opposite forces shaping the willingness to pay for insurance. For a fixed risk, the concavity of the utility function decreases the willingness to pay for insurance as coverage increases. With moral hazard, risk increases with coverage, which in turn means that willingness to pay for insurance increases with coverage. The net effect can then go either way. However, the reference individual is the less risk averse one, so that we can expect the moral hazard effect to dominate the concavity of the utility function effect. This is certainly true if the less risk averse individuals are almost risk neutral.

In the Appendix, we solve the model using Yaari's (1987) dual theory of preferences under risk and show that, although Properties 1 and 2 are naturally satisfied in this context, the marginal willingness to pay for insurance of the less risk averse individual is increasing with coverage, resulting in a 
positive correlation between risk and insurance purchase.

\section{Effect of social insurance}

If propitious selection does not necessarily produce negative correlation between risk and insurance purchases, it nevertheless has profound policy implications for social insurance. To see this, we now introduce a partial social insurance that agents can complement with extra private insurance. We assume that social insurance is pooling, with everybody paying the same premium and offered the same coverage rate. We show that the classical efficiency gain from social insurance through cross-subsidization is turned on its head when the marginal willingness to pay of the less risk averse individuals is increasing with coverage, as in Figure 3. We illustrate this result in Figure 4, where we measure total coverage rate (i.e. the sum of social and complementary private insurance) on the horizontal axis and total premium on the vertical axis. We assume that, with only private insurance, type $L$ 's incentive compatibility constraint is binding at equilibrium, so that there is overprovision on the private market, with type $L$ 's contract at point $A$ and type $H$ 's contract at $B^{\prime}$.

[Insert Figure 4: Pareto worsening public insurance] 
Consider that the social insurance coverage is less than or equal to the amount of private insurance the type $L$ would buy on the market in absence of any social insurance. So we do not force the less risk averse to buy more insurance than he would like (which would otherwise have an extra negative welfare effect). Therefore, type $L$ individuals' total coverage is unchanged after the introduction of social insurance (perfect crowding out). However, social insurance is pushing up the price of insurance for the less risk averse individuals because in equilibrium this type is less risky and thus crosssubsidizes the more risky type (i.e. the more risk averse individuals). In Figure 4, type $L$ 's equilibrium point moves from $A$ to $A$ ' when social insurance is introduced, so these individuals are made worse off. Further note that this utility loss increases with the extent of social insurance and with the proportion of type $H$ individuals.

This utility loss will increase the incentive for type $L$ to claim the contract intended for type $H$. As a result, the separation of the two types is made more difficult, which increases the overprovision to the more risk averse individuals required to separate them out. At the same time, type $H$ agents benefit from the cross-subsidization from type $L$. Graphically, the new equilibrium point for type $H$ agents (point $B$ ") is located to the right of point $B^{\prime}$ (because of increased overprovision), on type $L$ 's indifference curve through $A^{\prime}$ (indicating that type $L$ 's incentive constraint is binding) and below the ac- 
tuarially fair contract curve for type $H$ (because of the cross-subsidization). Note that the vertical distance between $B$ " and $\pi(H)$ is decreasing with the proportion of type $H$ individuals. It is clear from Figure 4 that, if the proportion of type $H$ is large enough, then they will also lose when introducing social insurance. We then have the following result.

Result 3 Under Properties 1-2, if the marginal willingness to pay for insurance of the less risk averse individuals is increasing with coverage rates, then the introduction of social insurance is Pareto inferior when the proportion of more risk averse individuals is sufficiently high.

The intuition for this result is as follows: less risk averse agents have a lower risk in equilibrium due to lower coverage and thus suffer from being pooled with more risky individuals. This in turn induces the private insurance market to increase overprovision to separate the more risk averse individuals. If more risk averse agents are numerous enough, the incentive cost dominates the cross-subsidy benefit so that they also lose from social insurance.

\section{Conclusion}

The cherry picking/propitious (or advantageous) selection argument assumes that individuals differ in risk aversion and that those with high risk aversion 
are more likely both to purchase insurance and to exert precaution. Those with less risk aversion will tend to buy less insurance and to act less cautiously. The presumed implication is that those buying more insurance have also the lower accident probabilities (i.e. negative correlation between risk and insurance purchases), contrarily to the prediction of classical insurance models.

We propose a simple three-stage model to formalize this argument, check its internal consistency and its implications. We list two properties that formalize the cherry picking line of reasoning in our model: regularity (more risk averse individuals exert more care) and single-crossing (more risk averse individuals have stronger preference for insurance). We first show that a pooling equilibrium is incompatible with these two properties. We then show that the negative correlation between risk and coverage is not guaranteed even when these two properties are satisfied: a negative correlation at equilibrium also requires that the marginal willingness to pay for insurance of the less risk averse individuals be decreasing with coverage. The reason is that there is overprovision of insurance in equilibrium. We provide in the Appendix an example where the two properties are satisfied and where the correlation between equilibrium risk and coverage bought is positive. Finally, we also point out the possibility in this context for social insurance to be Pareto damaging. 
Our model is admittedly not the only way to formalize the propitious selection argument. As pointed out by a referee, if we began with a slightly different model (incorporating elements like transaction costs, loading factors or uncertainty about one's own risk) and added our propitious selection assumptions, we might obtain different results. Also, our contribution is exclusively theoretical. We hope that our paper will drive researchers to develop formally other models incorporating propitious selection and to test them empirically. 


\section{Appendix}

\section{A Example of propitious selection with the dual theory of choice under risk.}

We model individuals' risk preferences using Yaari's (1987) theory, which is dual to the expected utility theory in the sense that it is linear in wealth but non linear in probabilities. This formulation allows us to separate attitude towards risk from attitude towards wealth: with Yaari's approach, risk aversion is entirely driven by a transformation of probabilities whereby bad outcomes are given more weight while good outcomes are given less weight.

Following De Donder and Hindriks (2003), the utility function of an individual who exerts an effort $e$ with $\operatorname{cost} c(e)$, faces a loss probability $p(e)$ and who buys the insurance contract $(\pi, \delta)$ is

$$
\begin{aligned}
u(\pi, \delta, p, e ; \alpha)= & (1+\alpha) p(e)(w-\pi-(1-\delta) L) \\
& +(1-(1+\alpha) p(e))(w-\pi)-c(e) \\
= & w-\pi-(1+\alpha) p(e)(1-\delta) L-c(e)
\end{aligned}
$$

where $w$ denotes his exogenous income and $\alpha \geq 0$ is his risk aversion parameter. In words, the individual overestimates by a fraction $\alpha$ his expected 
financial damage. The utility without insurance is

$$
u(0,0, p, e ; \alpha)=w-(1+\alpha) p(e) L-c(e)
$$

and the reservation premium is

$$
r(\delta, p ; \alpha)=(1+\alpha) p(e) \delta L
$$

Therefore risk aversion $\alpha$ in our model takes the form of a relative markup over the actuarially fair price.

We first solve for the optimal precaution choice given the insurance contract $(\delta, \pi)$ bought:

$$
\max _{e} w-\pi-(1+\alpha) p(e)(1-\delta) L-c(e)
$$

We assume that $c(e)=e^{2}, L=1, p(e)=\frac{(1-e)}{2} \in\left[0, \frac{1}{2}\right]$ for $e \in[0,1]$ and define $\theta=(1+\alpha) / 2$ (with $\theta \in\left[\frac{1}{2}, 1\right]$ ). The optimal precaution choice for type $\theta$ is

$$
e_{\theta}(\delta)=\frac{(1-\delta) \theta}{2} \in\left[0, \frac{1}{2}\right]
$$

and the corresponding risk for type $\theta$ is

$$
p_{\theta}(\delta)=\frac{1}{2}-\frac{(1-\delta) \theta}{4} \in\left[\frac{1}{4}, \frac{1}{2}\right]
$$

Property 1 (regularity) is then satisfied, and the induced utility function for type $\theta$ from insurance contract $(\delta, \pi)$ is

$$
\begin{aligned}
V_{\theta}(\delta, \pi) & =w-\pi-2 \theta(1-\delta) p_{\theta}(\delta)-c\left(e_{\theta}(\delta)\right) \\
& =w-\pi-\theta(1-\delta)+\frac{(1-\delta)^{2}}{4} \theta^{2} .
\end{aligned}
$$


With our functional forms, marginal willingness to pay for insurance (using an envelope argument with respect to precaution choice) is

$$
\left.\frac{d \pi}{d \delta}\right|_{V_{\theta}}=\theta-\frac{(1-\delta)}{2} \theta^{2} \equiv s(\delta, \theta) .
$$

We thus obtain naturally the single-crossing condition (property 2).

We turn to the insurance contracts offered to the individuals. The contract curve composed of all fair contracts proposed to an individual of type $\theta$ is given by

$$
\pi(\delta, \theta)=\left(\frac{1}{2}-\frac{(1-\delta)}{4} \theta\right) \delta
$$

where $\delta \in[0,1]$.

The slope of this contract curve in the space $(\pi, \delta)$ is given by

$$
\frac{\partial \pi(\delta, \theta)}{\partial \delta}=\frac{1}{2}-\frac{\theta(1-2 \delta)}{4} \equiv \sigma(\delta, \theta) .
$$

It is readily verified that the contract curve is convex, due to moral hazard. Moreover, we have $\pi(0, \theta)=0, \pi(1, \theta)=1 / 2$ (since no precaution is exerted and everybody shares the same risk) and $\pi(\delta, L)>\pi(\delta, H)$ for all $0<\delta<1$ and all $L<H$, reflecting the higher risk level of less risk averse agents.

The reader can check that the optimal choice of an insurance contract along the actuarially fair contract curve of each individual implies that more risk averse agents buy more coverage. On the other hand, moral hazard results in both indifference curves and contract curves being convex in the $(\pi, \delta)$ space, with indifference curves less convex than contract curves (because 
utility functions incorporate the cost of precaution while contract curves do not). Using the dual theory of risk preferences, we then end up with the same situation as the one described in the text: although properties 1 and 2 are satisfied, propitious selection generates a positive correlation between risk and insurance purchase. 


\section{References}

[1] Cawley, John and Tomas Philipson. (1999). "An empirical examination of information barriers to trade in insurance," American Economic Review $89,827-846$.

[2] Chiappori, Pierre-André, Bruno Jullien, François Salanié and Bernard Salanié. (2006). "Asymmetric Information in Insurance: General Testable Implications," Rand Journal of Economics 37 (4), 783-798.

[3] Chiappori, Pierre-André and Bernard Salanié. (2000). "Testing for Asymmetric Information in Insurance Markets," Journal of Political Economy 108, 56-78.

[4] Clyde, Alexandra T., David Hemenway and John T. Nagurney. (1996). "Seat Belt Use, Insurance Status, and Hospital Bad Debt," Journal of Trauma-Injury Infection \& Critical Care 41(1),100-104.

[5] Cutler David M., Finkelstein, Amy and Kathleen M. McGarry. (2008). "Preference heterogeneity and Insurance markets: Explaining a puzzle of insurance," NBER Working Paper 13746.

[6] De Donder, Philippe and Jean Hindriks. (2003). "The politics of redistributive social insurance," Journal of Public Economics 87, 2639-2660. 
[7] De Feo, Giuseppe and Jean Hindriks. (2005). "Efficiency of competition in insurance markets with adverse selection," Discussion Paper 2005-42, Université Catholique de Louvain.

[8] de Meza, David and David C. Webb. (2001). "Advantageous Selection in Insurance Markets," Rand Journal of Economics 32 (2), 249-262.

[9] Eeckhoudt, Louis and Christian Gollier. (2005). "The Impact of Prudence on Optimal Prevention," Economic Theory 26 (4), 989-994.

[10] Finkelstein, Amy and Kathleen M. McGarry. (2003). Private information and its effect on market equilibrium: new evidence from long-term care insurance," NBER Working Paper 9957.

[11] Hemenway, David. (1990). "Propitious Selection," The Quarterly Journal of Economics 105, 1063-69.

[12] Hemenway, David. (1992). "Propitious Selection in Insurance," Journal of Risk and Uncertainty 5, 247-51.

[13] Jullien, Bruno, Bernard Salanié and François Salanié. (1999). "Should More risk averse Agents Exert More Effort?," The Geneva papers on Risk and Insurance Theory 24, 19-28. 
[14] Jullien, Bruno, Bernard Salanié and François Salanié. (2007). "Screening risk averse Agents under Moral Hazard: single-crossing and the CARA case," Economic Theory 30 (1), 151-169.

[15] Lloyd, LE., M. Lauderdale and TG Betz. 1987. "Motorcycle deaths and injuries in Texas: helmets make a difference," Texas Medicine 83, 30-33.

[16] Nelson, David E., Timothy D. Peterson, Terence L. Chorba, Owen J. Devine and Jeffrey J. Sacks (1993). "Costs savings associated with increased safety belt use in Iowa, 1987-1988," Accident Analysis and Prevention $25(5), 521-528$.

[17] Saito, Kuniyoshi. (2006). "Testing for Asymmetric Information in the Automobile Insurance Market Under Rate Regulation," Journal of Risk E Insurance 73 (2) , 335-356.

[18] Villeneuve, Bertrand. (2000). "The Consequences for a Monopolistic Insurer of Evaluating Risk Better than Customers: The Adverse Selection Hypothesis Reversed," The Geneva papers on Risk and Insurance Theory $25,65-79$.

[19] Viscusi, W. Kip and Jahn J. Hakes. (2008). "Risk beliefs and smoking behavior," Economic Enquiry 46 (1), 45-59. 
[20] Yaari, Menahem E. (1987). "The dual theory of choice under risk," Econometrica 55 (1), 95-115. 
Figure 1: Non-existence of pooling equilibria

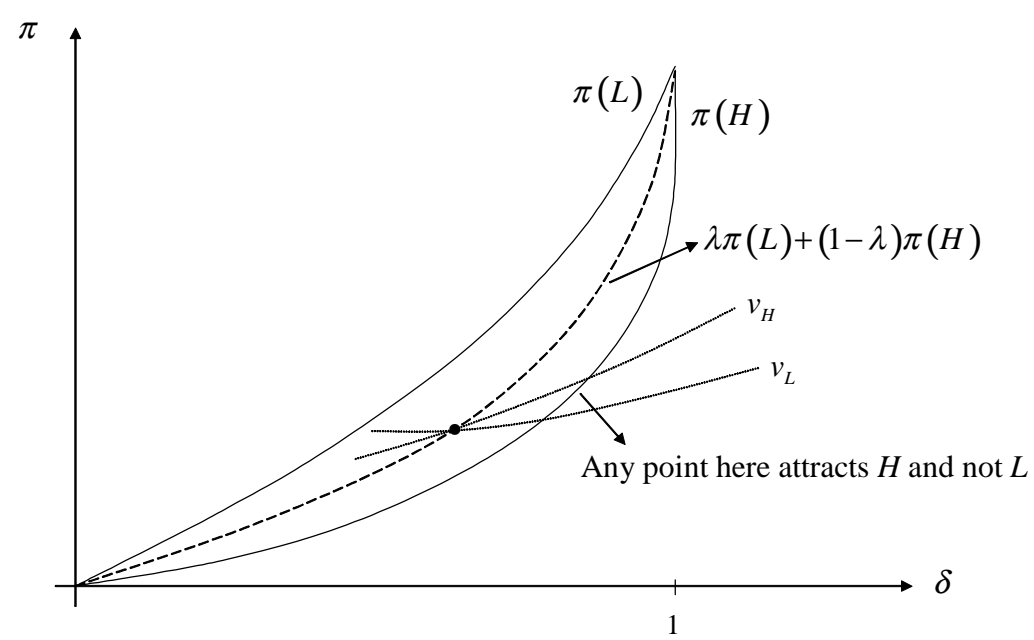


Figure 2: Separating equilibrium with overinsurance

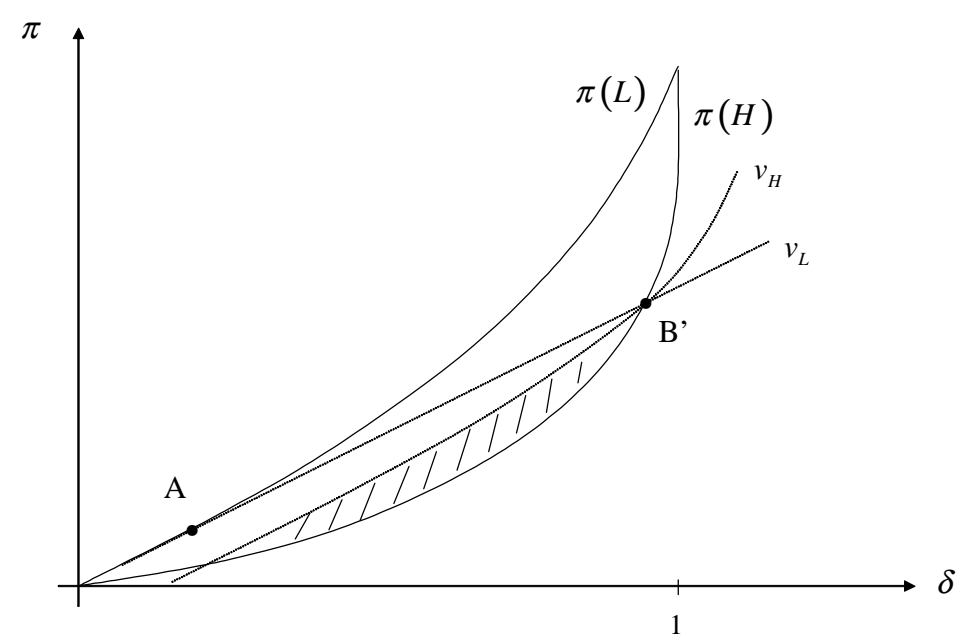


Figure 3: Relative risks in separating equilibria

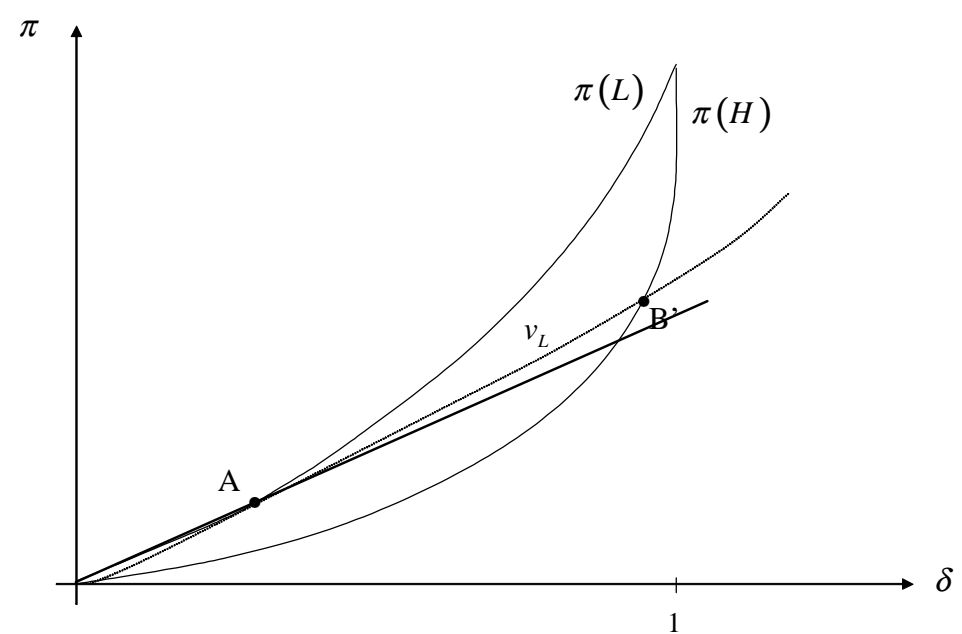


Figure 4: Pareto worsening social insurance

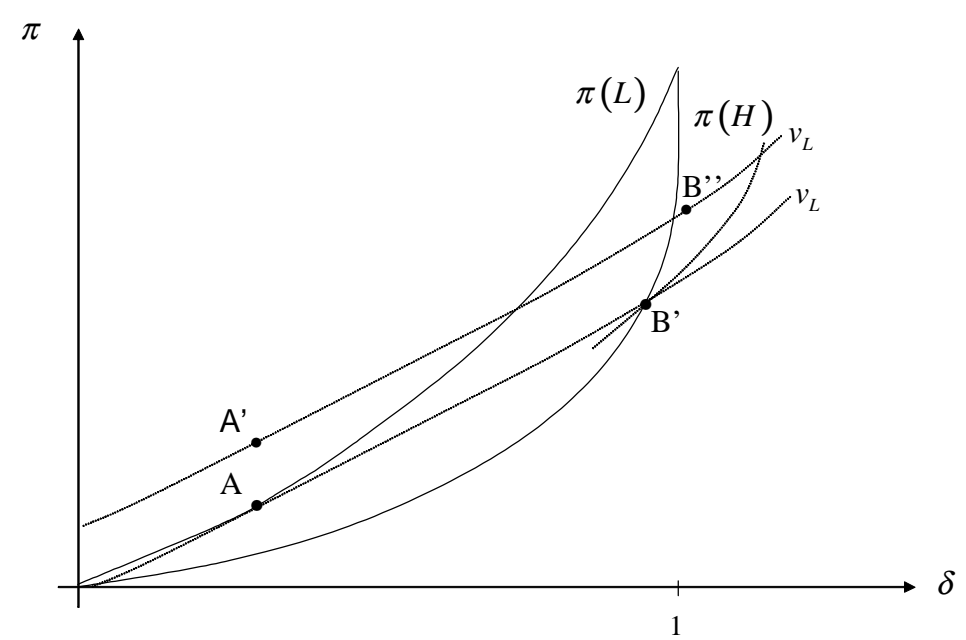

